\title{
Comparison of balance skills of visually impaired and non-impaired judo athletes and goalball/futsal players
}

\author{
Aras D. ${ }^{1 \mathrm{ABCD}}$, Güler Ö. ${ }^{\mathrm{ABC}}$, Gülü M. ${ }^{1 \mathrm{ABC}}$, Akça F. ${ }^{1 \mathrm{ABD}}$, Arslan E. ${ }^{1 \mathrm{BD}}$, Akalan C. ${ }^{1 \mathrm{CD}}$
}

${ }^{1}$ Faculty of Sport Sciences, Department of Coaching Education, Ankara University, Ankara, Turkey

${ }^{2}$ School of Physical Education and Sports, Department of Coaching Education, Siirt University, Siirt, Turkey

Authors' Contribution: A - Study design; B - Data collection; C - Statistical analysis; D - Manuscript Preparation; E - Funds Collection.

\begin{abstract}
Purpose: In order to sustain the performance in sport, it is necessary to constantly struggle with the factors which disrupt balance, and maintain the desired balance. The purpose of the present study is to compare and demonstrate the effects of sight grade on static and dynamic balance, and fall risk parameters in visually impaired and non-impaired judo athletes and goalball/futsal players.

Material: $\quad$ A total of 26 male athletes (13 Judo, 13 Goalball/Futsal) participated in the study voluntarily. The participants performed two balance tests as Overall Stability Test and Fall Risk Test with the eyes open and eyes closed. The parameters observed were static and dynamic overall stability, anterior-posterior, and medial-lateral index, and fall risk.

Results: $\quad$ According to the findings, there were significant differences in all the parameters with the eyes open and eyes closed conditions in visually non-impaired athletes regardless of the sport branch, while visually impaired athletes showed no significant difference. However, more loss of balance was observed in all the parameters for visually impaired athletes.

Conclusions: These findings show that visual system has a crucial role on balance, and athletes with visually impaired have more advanced vestibular system and proprioceptive senses to maintain their balance. It was also understood that visually non-impaired athletes tend to show more deteriorated balance level when their eyes were closed. Future studies could examine the vestibular and proprioceptive senses besides visual system to provide information about how balance is affected from other systems.

Keywords: Balance, visually impaired, judo, goalball, futsal.
\end{abstract}

\section{Introduction}

Balance has been defined as the ability to maintain the body position for a desired period of time [1]. Systems constituting balance and/or postural control are vestibular, visual, and proprioceptive senses and afferent pathways between these senses and the central nervous system $[2,3,4]$. An impairment in one of these components of balance influences postural stability negatively [3]. In order to sustain the performance in sport, it is necessary to constantly struggle with the factors which disrupt balance, and maintain the desired balance $[5,6]$. Balance is generally divided into static and dynamic balance. Static balance expresses to keep the center of gravity in the support center with minimal movements. Dynamic balance refers to maintain the balance during motion, and return the body to stabilized position from the movement [7]. Another definition of dynamic balance is that the regulation of the posture with minimum movement on unsteady grounds, reform, and maintenance $[8,9]$. Both static and dynamic balance level have role in Judo and Goalball/Futsal games $[10,11]$. It was stated that postural instability, which causes lack of balance, can reduce the force output about $50 \%$ [6].

Goalball and Judo were two sport branches with the highest injury rate in the Paralympic Games of London, and they were performed by visually impaired athletes [12]. Seeing that postural stability is also known as a tool to evaluate the injury risk in sport [13]. Postural stability

(C) Aras D., Güler Ö., Gülü M., Akça F., Arslan E., Akalan C., 2018 doi:10.15561/20755279.2018.0602 and a developed level of balance could be considered as substantial components of postural control of visually impaired individuals [6, 14-16].

To our knowledge, there's no study in the literature comparing the balance skills of visually impaired and non-impaired judo athletes, and goalball/futsal players according to their sight grade. Therefore, the aim of our study is to compare and demonstrate the effects of sight grade on static and dynamic balance, and fall risk parameters in visually impaired and non-impaired judo athletes and goalball/futsal players.

\section{Material and methods}

Participants: A total of 26 athletes (13 male Judo athletes and 13 male Goalball/Futsal players) participated in the study voluntarily. The demographic characteristics of the participants are shown in Table 1.

Procedure: To determine the static and dynamic balance levels of visually impaired and non-impaired Judo and Goalball/Futsal players, subjects were tested in two different conditions. The first balance tasks were done with the eyes open, and second tasks were done with the eyes closed. In the current study visually impaired and non-impaired Judo athletes and visually impaired Goalball players and non-impaired Futsal players were compared with each other's. Despite the fact that Goalball is played by only visually impaired participants, Futsal players were chosen to make a comparison as a very similar sport branch to Goalball.

Balance performances of the participants were 
Table 1. Demographic characteristics of the participants.

\begin{tabular}{llllllll}
\hline Group & Branch & $\begin{array}{l}\text { Sight grade } \\
(\%)\end{array}$ & Age (year) & $\begin{array}{l}\text { Body height } \\
\text { (cm) }\end{array}$ & $\begin{array}{l}\text { Body weight } \\
\text { (kg) }\end{array}$ & $\begin{array}{l}\text { Body Mass } \\
\text { Index (BMI) }\end{array}$ & $\begin{array}{l}\text { Percent } \\
\text { body fat (\%) }\end{array}$ \\
\hline $\begin{array}{l}\text { Visually } \\
\text { impaired }\end{array}$ & Judo (6) & $83.33 \pm 2.58$ & $32 \pm 4.29$ & $173 \pm 10.33$ & $81.72 \pm 15.96$ & $27.05 \pm 1.98$ & $24.22 \pm 2.21$ \\
& (6) & $82.50 \pm 2.74$ & $26.50 \pm 3.02$ & $178 \pm 11.66$ & $78.25 \pm 9.99$ & $24.73 \pm 3.01$ & $21.22 \pm 8.70$ \\
\multirow{2}{*}{$\begin{array}{l}\text { Non- } \\
\text { impaired }\end{array}$} & Judo (6) & 100 & $19.57 \pm 1.72$ & $174.71 \pm 7.34$ & $73.34 \pm 7.70$ & $23.99 \pm 1.82$ & $17.99 \pm 3.83$ \\
& Futsal & 100 & $32 \pm 4.29$ & $173 \pm 10.33$ & $81.72 \pm 15.96$ & $27.05 \pm 1.98$ & $24.22 \pm 2.21$ \\
\hline
\end{tabular}

determined in the performance laboratory. Besides the balance levels, the body composition of the participants was also measured. After measuring body composition, dynamic and static balance levels were determined with 20 minutes of rests, and each one recorded with the eyes open eyes closed conditions.

Subjects were asked to refrain from any food intake for three hours before the measurements and to avoid caffeine, alcohol and strenuous exercise for 48 hours before tests. Subjects were also informed about the tasks on the first day of the study. All subjects signed an informed consent form, and this study was conducted in accordance with the Declaration of Helsinki 2013.

Body composition analysis: To determine the body composition a bioelectrical impedance analyzer (PlusAvis 333, Jawon Medical, South Korea) was used. The parameters used were; Body weight (BW), percent body fat (PBF), and body mass index (BMI).

Balance test: Balance tasks were performed on Biodex Balance System SD (Biodex Medical Systems, Shirley, NY). All the participants were told to take off their shoes and socks before testing. Participants we also told to stand straight during each test with their hands on their hips, and their feet shoulder width apart. Participants performed two different balance tests as overall stability test (OSI) and fall risk test (FR). All tests were performed one with the eyes open and one with the eyes closed conditions. The overall stability test was executed three times, and lasted for 20 seconds with the 10 -second resting times. The parameters obtained from OSI balance tests were; overall stability index static-dynamic (S-OSI, D-OSI), anterior-posterior stability index static-dynamic (S-APSI, D-APSI), and medial-lateral stability index static-dynamic (S-MLSI, D-MLSI). The FR lasted was executed twice, and for 30 seconds with the 10 -second resting times.

Statistical Analyses: Normality of the distribution was analyzed using Shapiro-Wilk test. According to the distribution of the data Paired Sample t-Test or Wilcoxon Test was used for intra group analyses, and Independent Sample t-Test or Mann-Whitney U Test was chosen for inter group analyses. A probability level of 0.05 was established to determine statistical significance. All statistical analyses were conducted using SPPS version 20 (SPSS Inc., Chicago, IL).

Table 2. The static and dynamic OSI, APSI, MLSI, and FR values and their inter- and intra-group mean differences of visually impaired and non-impaired Judo athletes during with the eyes open and closed conditions.

\begin{tabular}{|c|c|c|c|c|}
\hline Parameters & Sight condition & Visually impaired & Non-impaired & $P$ \\
\hline & Eyes open & $1.25 \pm 0.55$ & $0.37 \pm 0.95$ & $0.001 *$ \\
\hline S-OSI & Eyes closed & $1.60 \pm 0.70$ & $0.79 \pm 0.33$ & $0.018^{*}$ \\
\hline$P$ & & 0.096 & $0.012 *$ & \\
\hline & Eyes open & $2.73 \pm 2.09$ & $0.90 \pm 0.27$ & $0.003 *$ \\
\hline D-OSI & Eyes closed & $4.33 \pm 3.58$ & $2.41 \pm 1.69$ & $0.044 *$ \\
\hline$P_{-}$ & & 0.053 & $0.018^{*}$ & \\
\hline$C A D C$ & Eyes open & $0.85 \pm 0.48$ & $0.20 \pm 0.06$ & $0.004 *$ \\
\hline S-APSI & Eyes closed & $1.18 \pm 0.56$ & $0.64 \pm 0.37$ & 0.062 \\
\hline$P_{-}$ & & 0.083 & $0.016^{*}$ & \\
\hline D-APSI & Eyes open & $1.88 \pm 1.37$ & $0.60 \pm 0.15$ & $0.031 *$ \\
\hline $\boldsymbol{P}$ & & $\begin{array}{l}3.03 \pm 2.43 \\
0.058\end{array}$ & $\begin{array}{l}1.51 \pm 0.88 \\
0.018^{*}\end{array}$ & 0.113 \\
\hline$C_{-} \mathrm{Micl}^{2}$ & Eyes open & $0.72 \pm 0.48$ & $0.23 \pm 0.10$ & $0.022 *$ \\
\hline $\begin{array}{l}\text { S-MLSI } \\
P\end{array}$ & Eyes closed & $\begin{array}{l}0.92 \pm 0.52 \\
0.114\end{array}$ & $\begin{array}{l}0.34 \pm 0.10 \\
0.047^{*}\end{array}$ & $0.037 *$ \\
\hline D-MISI & Eyes open & $1.62 \pm 1.34$ & $0.51 \pm 0.23$ & $0.005^{*}$ \\
\hline $\begin{array}{l}\text { D-IMLSI } \\
P\end{array}$ & Eyes closed & $\begin{array}{l}2.37 \pm 1.86 \\
0.074\end{array}$ & $\begin{array}{l}1.66 \pm 2.27 \\
0.018^{*}\end{array}$ & 0.246 \\
\hline- & Eyes open & $2.67 \pm 2.05$ & $0.81 \pm 0.29$ & $0.037^{*}$ \\
\hline PR & Eyes closed & $\begin{array}{l}2.82 \pm 2.63 \\
0.786\end{array}$ & $\begin{array}{l}1.70 \pm 0.50 \\
0.017^{*}\end{array}$ & 0.731 \\
\hline
\end{tabular}

S-OSI: Static overall stability index; D-OSI: Dynamic overall stability index; S-APSI: Static anterior-posterior stability index; D-APSI: Dynamic anterior-posterior stability index; S-MLSI: Static medial-lateral stability index; D-MLSI: Dynamic medial-lateral stability index; FR: Fall risk. 


\section{Results}

The results derived from the balance tests of visually impaired and non-impaired judo athletes are shown in the Table 2.

As seen in Table 2, the visually non-impaired athletes reached better balance and fall risk scores. However, all the balance and fall risk parameters showed significant deteriorations for the visually non-impaired athletes. No significant change was observed in the visually impaired group. Moreover, all the balance and fall risk parameters between visually impaired and non-impaired athletes were significantly difference during the eyes open condition. Only significant changes were in the S-OSI, D-OSI, and S-MLSI parameters during the eyes closed condition.

The findings obtained from the balance tests of visually impaired and non-impaired goalball and futsal players are shown in the Table 3.

In the accordance with the Table 3 there was no significant change in any of the static or dynamic balance, and fall risk parameters in visually impaired athletes according to sight condition. On the contrary visually nonimpaired athletes showed significant impairments in all of the balance and fall risk parameters when their eyes were closed. Even though visually non-impaired athletes had better values in all of the parameters, the only significant differences were observed in the eyes open condition.

\section{Discussion}

The purpose of the current study was to compare and demonstrate the effects of sight grade on static and dynamic balance, and fall risk parameters in visually impaired and non-impaired judo athletes and goalball/ futsal players.

When the results were examined it could be clearly seen that there was a significant difference in all the balance parameters with the eyes open and eyes closed conditions in visually non-impaired athletes regardless of their sport branch. Accordingly, it was understood that visually non-impaired athletes tend to show more deteriorated balance level when their eyes were closed. There was not found a statistically significant difference in any of the balance parameters of visually impaired athletes depending on their sight condition. There are some other studies showing that blind individuals could produce better scores in some tasks than visually impaired or non-impaired individuals $[17,18]$. Its reason could be that the athletes with visually impaired, has more advanced vestibular system and proprioceptive senses to maintain their balance [18]. Nevertheless, blind individuals since birth improve their perception level from other sources due to lack of vision [18]. Hence, the visually impaired people probably tend to use proprioceptive system, and muscular feedback more, while visually non-impaired individuals use mostly visual system $[19,20]$.

Table 3. The static and dynamic OSI, APSI, MLSI, and FR values and their inter- and intra-group mean differences of visually impaired and non-impaired Goalball and Futsal players during with the eyes open and closed conditions.

\begin{tabular}{lllll}
\hline Parameters & Sight condition & Visually impaired & Non-impaired & $\boldsymbol{P}_{-}$ \\
\hline S-OSI & Eyes open & $1.30 \pm 0.69$ & $0.54 \pm 0.13$ & $0.014^{*}$ \\
$\boldsymbol{P}_{-}$ & Eyes closed & $2.05 \pm 1.10$ & $1.24 \pm 0.61$ & 0.124 \\
D-OSI & Eyes open & 0.204 & $0.018^{*}$ & $0.026^{*}$ \\
$\boldsymbol{P}_{-}$ & Eyes closed & $3.42 \pm 0.98$ & $1.36 \pm 0.23$ & 0.767 \\
S-APSI & & 0.242 & $3.29 \pm 0.54$ & $0.045^{*}$ \\
$\boldsymbol{P}_{-}$ & Eyes open & $0.88 \pm 0.50$ & $0.000^{*}$ & 0.064 \\
D-APSI & Eyes closed & $1.62 \pm 0.97$ & $0.44 \pm 0.14$ & $0.007^{*}$ \\
$\boldsymbol{P}_{-}$ & & 0.204 & $0.81 \pm 0.34$ & 0.867 \\
S-MLSI & Eyes open & $1.97 \pm 0.58$ & $0.017^{*}$ & $0.002^{*}$ \\
$\boldsymbol{P}_{-}$ & Eyes closed & $2.15 \pm 0.59$ & $1.14 \pm 0.33$ & 0.234 \\
D-MLSI & & 0.683 & $2.10 \pm 0.45$ & $0.015^{*}$ \\
$\boldsymbol{P}_{-}$ & Eyes open & $1.28 \pm 0.51$ & $0.36 \pm 0.29$ & $0.027^{*}$ \\
FR & Eyes closed & $1.07 \pm 0.84$ & $0.64 \pm 0.30$ & 0.888 \\
$\boldsymbol{P}_{-}$ & Eyes open & $1.37 \pm 0.81$ & $0.003^{*}$ & $0.011^{*}$ \\
\hline
\end{tabular}

S-OSI: Static overall stability index; D-OSI: Dynamic overall stability index; S-APSI: Static anterior-posterior stability index; D-APSI: Dynamic anterior-posterior stability index; S-MLSI: Static medial-lateral stability index; D-MLSI: Dynamic medial-lateral stability index; FR: Fall risk. 
However, more loss of balance was observed in all the parameters of visually impaired athletes. The significant differences were observed in all parameters only with the eyes open condition for Goalball/Futsal players. In addition to the eyes open condition, the S-OSI, D-OSI, S-MLSI were also significantly different with the eyes closed condition in Judo athletes. It is known that Judo athletes' balance ability is mostly depended visual feedback [21]. Thus, observing more loss of balance in Judo athletes than Goalball players could be accepted. These findings show that visual system has a substantial role on balance. According to Klavina and Jekabsone (2014) almost $80 \%$ of the stimuli is perceived through the optic canal. Therefore, an insufficiency of this process could affect the level of static balance [22]. Tomomitsu et al. (2013) stated that the level of static balance tends to decrease when visual stimuli is limited [23].

This is the first study to compare the balance skills of visually impaired and non-impaired Judo athletes and Goalball/Futsal players. Being one of the skill-related components of physical fitness, balance has a crucial role in the quality of life of all individuals [24]. A reduction in balance level can be a reason of musculoskeletal injuries and functional losses in all age groups [25]. Having an enhanced level of balance is substantial not only for daily physical activities but also for sport performance. Thus, a number of studies investigated the relationship between balance and sport performance [26-28].

Judo and Soccer are sport branches in which postural control has a critical role [29]. Thus, researchers did some studies investigating the balance level in these sports. For instance, Kurz et al. (2018) reported that 4 weeks of balance training decreased postural sway and increased the sport performance significantly in visually impaired cross-country skiers $(p<005)$ [30]. Bednarczuk et al. (2017) investigated the static balance level of 37 goalball players and 20 shooters, and found no significant difference between them [31]. In another study Bednarczuk et al. (2017) evaluated the static balance of 42 male and 23 female visually impaired goalball players. Their results showed that there was no significant difference between the male and female athletes. Only the athletes with more than 10 years of experience had better static balance scores $(p<0.05)$ [32]. Krzak et al. (2015) reported that playing goalball provides significant enhancements on motor abilities in visually impaired individuals [33].

Earlier studies showed that balance level of trained people is better than untrained [34, 35]. However, it is known that to train the balance has an important role not only for untrained individuals but also professional athletes [36]. Behm and Colado (2012) stated that 105 $\%$ enhance in functional performance brings about $31 \%$ increase in balance [37]. There are also studies showing that balance level of visually impaired athletes could be improved even though their lack of vision $[30,38]$.

\section{Conclusions}

As a result of our study, it could be inferred that to train the balance with the eyes closed could affect the sport performance in individual or team sports. In addition, future studies could examine the effects of vestibular system, and proprioceptive senses besides visual system. These examinations could provide information about how balance is affected from these systems in visually impaired individuals.

\section{Financial support:}

There is no financial support for the present study.

\section{Conflict of interest}

The authors declare no conflict of interest.

\section{References}

1. Thompson WR. ACSM'S Resources for the Personel Trainer. Baltimore MD: Wolters Kluver Lippincott Williams \& Wilkins; 2010.

2. Irrgang JJ, Whitney S, Cox E. Balance and proprioseptive training for rehabilitation of the lower extremity. Journal of Sport Rehabilitation, 1994; 3: 68- 83. https://doi.org/10.1123/jsr.3.1.68

3. Muehlbauer T, Gollhofer A, Granacher U. Association of balance, strength, and power measures in young adults. Journal of Strength and Conditioning Research, 2013;27(3): 582-589. https://doi.org/10.1519/JSC.0b013e31825c2bab

4. Shumway-Cook A, Woollacott MH. Motor Control: Translating Research into Clinical Practice. Baltimore MD: Wolters Kluver; 2017.

5. Harringe M, Halvorsen K, Renstrom P, Werner S. Postural control measured as the center of pressure excursion in young female gymnasts with low back pain or lower extremity injury. Gait \& Posture, 2008; 28(1): 38- 45. https://doi.org/10.1016/j.gaitpost.2007.09.011

6. Behm DG, Muehlbauer T, Kibele A, Granacher U. Effects of strength training using unstable surfaces on strength, power and balance performance across the lifespan: A systematic review and meta-analysis. Sports Medicine, 2015; 45: 1645- 1669. https://doi.org/10.1007/s40279-015-0384-x

7. Winter DA, Patla AE, Frank JS. Assessment of balance control in humans. Medical Progress through Technology, 1990; 16: 31-50.

8. Kioumourtzoglou E, Derri V, Mertzanıdou O, Tzetzis G. Experience with perceptual and motor skills in rhythmic gymnastics. Perceptual and Motor Skills, 1997; 84(3 Pt 2): 1363- 1372. https://doi.org/10.2466/pms.1997.84.3c.1363

9. Pailard T, Noe F. Effect of expertise and visual contribution on postural control in soccer. Scandinavian Journal of Medicine \& Science in Sports, 2006; 16(5): 345- 348. https://doi.org/10.1111/j.1600-0838.2005.00502.x

10.Mononen K, Konttinen N, Viitasalo J, Era P. Relationships between postural balance, rifle stability and shooting accuracy among novice rifle shooters. Scandinavian Journal of Medicine \& Science in Sports, 2007; 17: 180-185.

11.Moran-Navarro R, Valverde-Conesa A, Lopez-Gullon JM, De la Cruz-Sanches E, Pallares JG. Can balance skills predict Olympic wrestling performance? Journal of Sport and Health Research, 2015; 7(1): 19-30.

12.Willick SE, Webborn N, Emery C, Blauwet CA, Pit- 
Grosheide P, Stomphorst J, Van de Vliet P, Marques NAP, Martinez-Ferre JO, Jordaan E, Derman W, Schwellnus M. The epidemiology of injuries in football at the London 2012 paralympic games. $P M \& R$ : the journal of injury, function, and rehabilitation, 2013; 47: 426-432.

13. Singla D, Veqar Z, Methods of postural assessment used for sports persons. Journal of clinical and diagnostic research, 2014; 8: 2-5.

14.Fitzpatrick R, McCloskey, DI. Proprioceptive, visual and vestibular thresholds for the perception of sway during standing in humans. The Journal of Physiology, 1994; 478: 173- 186. https://doi.org/10.1113/jphysiol.1994.sp020240

15.Ray CT, Horvat M, Croce R, Christopher Mason R, Wolf SL. The impact of vision loss on postural stability and balance strategies in individuals with profound vision loss. Gait Posture, 2008; 28: 58- 61. https://doi.org/10.1016/j.gaitpost.2007.09.010

16. Hazime FA, Allard P, Ide MR, Siqueira CM, Amorim CF, Tanaka C. Postural control under visual and proprioceptive perturbations during double and single limb stances: Insights for balance training. Journal of Body work and Movement Therapies, 2012; 16: 224- 229. https://doi.org/10.1016/j.jbmt.2011.02.003

17.Johnson-Kramer C, Sherwood D, French R, Canabal MY. Performance and learning of a dynamic balance task by visually impaired children. Clinical Kinesiology, 1992; 31: 3-6.

18. Nakata H, Yabe K. Automatic postural response systems in individuals with congenital total blindness. Gait Posture, 2001; 14: 36- 43. https://doi.org/10.1016/S0966-6362(00)00100-4

19.Horvat M, Ray C, Ramsey VK, Miszko T, Keeney R, Blash BB. Compensatory analysis and strategies for balance in individuals with visual impairments. Journal of Visual Impairment \& Blindness, 2003; 97: 695-703.

20.Houwen S, Visscher C, Lemmink KA, Hartman E. Motor skill performance of school-age children with visual impairments. Developmental Medicine and Child Neurology, 2008; 50: 139- 145. https://doi.org/10.1111/j.1469-8749.2007.02016.x

21.Paillard T, Costes SC, Lafont C, Dupui P. Are the differences in postural regulation according to the level of competition in judoists? BritishJournalofSports Medicine, 2002;36:304-305. https://doi.org/10.1136/bjsm.36.4.304

22.Klavina A, Jekabsone I. Static balance of persons with intellectual disabilities, visual impairment and without disabilities. European Journal of Adapted Physical Activity, 2014; 7(1): 50- 57. https://doi.org/10.5507/euj.2014.004

23.Tomomitsu MSV, Castilho Alonso A, Morimoto E, Bobbio TG, Greve JMD. Static and dynamic postural control in lowvision and normal-vision adults. Clinics, 2013;68(4):517-521. https://doi.org/10.6061/clinics/2013(04)13

24.Capodaglio P, Cimolin V, Tacchini E, Parisio C, Galli M. Balance control and balance recovery in obesity. Current Obesity Reports, 2012; 1: 166- 173. https://doi.org/10.1007/s13679-012-0018-7

25.Fullam K, Caulfield B, Coughlan GF, Delahunt E. Kinematic analysis of selected reach directions of the star excursion balance test compared with the y-balance test. Journal of Sport Rehabilitation, 2014; 23: 27- 35. https://doi.org/10.1123/JSR.2012-0114
26.Hrysomallis C. Balance ability and athletic performance. Sports Medicine, 2011; 41(3): 221- 232. https://doi.org/10.2165/11538560-000000000-00000

27.Pizzigalli L, Ahmaidi S, Rainoldi A. Effects of sedentary condition and longterm physical activity on postural balance and strength responses in elderly subjects. Sport Sciences for Health, 2014; 10: 135- 141. https://doi.org/10.1007/s11332-014-0184-y

28.Steinberg $\mathrm{N}$, Nemet $\mathrm{D}$, Pantonowitz $\mathrm{M}$, Zeev A, Hallumi M, Sindiani M, Eliakim, A. Longitudinal study evaluating postural balance of young athletes. Perceptual and Motor Skills, 2016; 122(1): 256- 279. https://doi.org/10.1177/0031512516628989

29.Jadzcak L, Grygorowicz M, Dzudzinski W, Sliwowski R. Comparison of static and dynamic balance at different levels of sport competition in professional and junior elite soccer players. Journal of Strength Conditioning Research in press, 2018; 12.

30.Kurz A, Lauber B, Franke S, Leukel C. Balance training reduces postural sway and improves sport-specific performance in visually impaired cross-country skiers. Journal of Strength Conditioning Research in press, 2018; 17. https://doi.org/10.1519/JSC.0000000000002597

31.Bednarczuk G, Wiszomirska I, Marszalek J, Rutkowska I, Waldemar S. Static balance of visually impaired athletes in open and closed skill sports. Polish Journal of Sport Tourism, 2017; 24: 10- 14. https://doi.org/10.1515/pjst-2017-0002

32.Bednarczuk G, Molik B, Margulec-Adamowicz N, Kosmol A, Wiszomirska I, Rutkowska I, Perkowski K. Static balance of visually impaired paralympic goalball players. International Journal of Sports Science \& Coaching, 2017; 12(5): 611- 617. https://doi.org/10.1177/1747954117727791

33.Krzak J, Slezynska M, Slezynski J. Goalball as an effective means of physical improvement for blind and visually impaired players. Medycyna Ogólna $i$ Nauki o Zdrowiu, 2015; 21(4): 383- 387. https://doi.org/10.5604/20834543.1186910

34.Leong HT, Fu SN, Ng GY, Tsang WW. Low-level taekwondo practitioners have better somatosensory organization in standing balance than sedentary people. European Journal of Applied Physiology, 2011; 111: 1787- 1793. https://doi.org/10.1007/s00421-010-1798-7

35.Baghbani F, Woodhouse LJ, Gaeini AA. Dynamic postural control in female athletes and non-athletes after a whole-body fatigue protocol. Journal of Strength and Conditioning Research, 2016; 30: 1942- 1947. https://doi.org/10.1519/JSC.0000000000001275

36. Taube W, Kullmann N, Leukel C, Kurz O, Amtage F, Gollhofer A. Differential reflex adaptations following sensorimotor and strength training in young elite athletes. International Journal of Sports Medicine, 2007; 28: 999- 1005. https://doi.org/10.1055/s-2007-964996

37.Behm D, Colado JC. The effectiveness of resistance training using unstable surfaces and devices for rehabilitation. International Journal of Sports Physical Therapy, 2012; 7: 226-241.

38.Mackowiak Z, Osinski W, Salamon A. The effect of sensorimotor training on the postural stability of visually impaired women over 50 Years of age. Journal of Women \& Aging, 2015; 27: 68- 80. https://doi.org/10.1080/08952841.2014.928140 


\section{Information about the authors:}

Aras D.; (Corresponding author); http://orcid.org/0000-0002-9443-9860; diclearasx@gmail.com; Ankara University Faculty of Sport Sciences, Department of Coaching Education; Golbasi, 06830, Ankara, Turkey.

Güler Ö.; https://orcid.org/0000-0002-5713-3395; ozkanguler@msn.com; Ankara University Faculty of Sport Sciences, Department of Coaching Education; Golbasi, 06830, Ankara, Turkey.

Gülü M.; https://orcid.org/0000-0001-7633-7900; mehmetgulu80@gmail.com; Ankara University Faculty of Sport Sciences, Department of Coaching Education; Golbasi, 06830, Ankara, Turkey.

Akça F.; https://orcid.org/0000-0002-0764-105X; firatakca@gmail.com; Ankara University Faculty of Sport Sciences, Department of Coaching Education; Golbasi, 06830, Ankara, Turkey.

Arslan E.; https://orcid.org/0000-0002-2933-6937; Ersanarslan1980@hotmail.com; Siirt University School of Physical Education and Sports, Department of Coaching Education; Kezer Yerleskesi, Pinarca Koyu 56100, Siirt, Turkey.

Akalan C.; https://orcid.org/0000-0001-7669-3358; cengizakalan@gmail.com; Ankara University Faculty of Sport Sciences, Department of Coaching Education; Golbasi, 06830, Ankara, Turkey.

Cite this article as: Aras D, Güler Ö, Gülü M, Akça F, Arslan E, Akalan C. Comparison of balance skills of visually impaired and non-impaired judo athletes and goalball/futsal players. Physical education of students, 2018;22(6):292-297. doi:10.15561/20755279.2018.0602

The electronic version of this article is the complete one and can be found online at: http://www.sportedu.org.ua/index.php/ PES/issue/archive

This is an Open Access article distributed under the terms of the Creative Commons Attribution License, which permits unrestricted use, distribution, and reproduction in any medium, provided the original work is properly cited (http:// creativecommons.org/licenses/by/4.0/deed.en).

Received: 04.09.2018

Accepted: 09.10.2018; Published: 26.12.2018 